\title{
Trigeminal Autonomic Cephalalgia by Neurogenic Palatine Compression: A Clinical Report and Review
}

\author{
Cefalea Autonómica Trigeminal por Compresión Neurogénica Palatina: Reporte de Caso y Revisión
}

"Ramirez Luis Miguel; **Ballesteros Luis Ernesto \& **:Sandoval Germán Pablo

RAMIREZ, L. M.; BALleSTEROS, L. E. \& SANDOVAL, G. P. Trigeminal autonomic cephalalgia by neurogenic palatine compression: A clinical report and review. Int. J. Morphol., 25(3):591-596, 2007.

SUMMARY: This clinical report presents the evolution of a possible intraoral traumatic trigeminal autonomic cephalalgia simulating a probable cluster headache. A 50-year-old female patient had severe right-hand side pain for 7 years with autonomic signs and symptoms, such as lacrimation, conjunctival injection, rhinorrhoea, nasal congestion, forehead perspiration, myosis and eyelid edema. The episodes of pain lasted 4 or 5 months with 3- or 4-month remission periods between the painful onsets. The headaches presented an episodic pattern (1 to 3 attacks daily) lasting three to six hours. The patient had used five prosthetic sets continuously ( $24 \mathrm{~h}$ ) for 20 years and the current prosthesis was 7 years old. Accidentally, after the alleviation of the maxillary denture due to it rested on a marked irritated incisive papilla the symptoms disappear. The patient has been periodically checked over a 5 year period since, without recurrence of her pain and autonomic symptomatology. The possible pathophysiology is discussed.

KEY WORDS: Sphenopalatine Ganglion; Incisive Papilla; Neurovascular Pain; Referred Pain; Temporomandibular Disorders.

\section{INTRODUCTION}

Primary and referred pain patterns depend on the intensity, localization and timing of the perceived pain stimulus which can produce neuropathic pain (Sessle et al., 1986). It can also simulate pathologies' apparently unconnected symptomatic behavior. Neuropathic pain pathophysiology and etiology are neither clear nor defined as yet. Peripheral neuropathic pain originates in the pathological change of nociceptive afferent nervous fibers caused by injured tissue being produced during the microtrauma or macrotrauma creating inappropriate peripheral or central pain signals (Moskowitz, 1984). Neuropathic and neurogenic pain can be expressed having vegetative implications, among other neurovascular manifestations (Ertsey et al., 2004).

Autonomic nervous system (ANS) involvement in producing pain is an ongoing debatable matter. The pain influences and is influenced by the ANS. Trigeminal autonomic cephalalgias (TAC) and Complex Regional Pain
Syndrome are presentations of pain having vegetative symptoms expressed as cranial autonomic symptoms which can be associated or disassociated with pain ( Bouhassira et al., 1994; Goadsby et al., 2001; Melis et al., 2002; Martins et al., 2004; Putzki et al., 2004). Such headache pain may be accompanied by considerable autonomic reactions in the head depending on parasympathetic and secondary sympathetic dysfunction (Hardebo, 1984; Goadsby \& Edvinsson, 1993; Jänig, 2003; Gottselig \& Messlinger, 2004).

TAC consists of three separate presentations: cluster headache, paroxysmal hemicrania and SUNCT (short-lasting unilateral neuralgiform headache with conjunctival injection and tearing). Although cluster headache is known to be a primary headache disorder, various clinical reports have stated that it is a secondary presentation from multiple origins (Tfelt-Hansen et al., 1982; Sacquegna et al., 1982; Kudrow et al., 1984, Romoli \& Cudia, 1988; Appelbaum \& Noronha, 1989; Gawel et al., 1989; Hannerz, 1989; Formisano et al.,

\footnotetext{
Odontology - Prosthetic Dentistry and Temporomandibular Disorders. Medical Education in Orofacial-Otic referred symptoms. Associate Professor of Morphology - Department of Basic Sciences - Medicine Faculty - Universidad Industrial de Santander - Bucaramanga - Colombia.

** Medical Doctor with Degree in Anatomy. Basic Sciences Department Director. Professor of Morphology - Department of Basic Sciences - Medicine Faculty - Universidad Industrial de Santander. Bucaramanga - Colombia.

*** Otolaryngology. Surgery Professor - Medicine Faculty - Universidad Industrial de Santander. Bucaramanga - Colombia.
} 
1990; West \& Todman, 1991; Koenigsberg et al., 1994; Cremer et al., 1995; Taub et al., 1995; Muñoz et al., 1996; Evers et al., 1997; Heidegger et al., 1997; Rosebraugh et al., 1997; Piovesan et al., 2001; Soros et al., 2001; Albertyn et al., 2004). Cluster headaches mimicking the appearance of these situations' must be kept in mind, such as neurovascular pain disorders or atypical TAC presentations or neurovascular variants (Rozen, 2002).

Patient complaints almost fulfilled the criteria for a cluster-type headache in this clinical report. The present symptomatology closely resembled a probable cluster headache (IHS ICHD-II, 2004). Cluster headache is an important, but uncommon, type of headache, having an estimated 10-70 per 1,000 people prevalence, whereas migraine is in the 100-150 range. This neurovascular disorder has a rare family history. This pathology commonly begins to presents itself in people aged 30 to 40 and is more frequently present in men than women ( $86 \%$ male preponderance)( Sjaastad \& Bakketeig, 2003). Ekbom et al. (2002) found significant variance in the male to female ratio regarding age of onset (predominance of males aged 30-49 but more common in females after age 50). The pain is intense and excruciating, having a strictly unilateral location that is commonly manifested in the trigeminal maxillary and ophthalmic areas (oculo-fronto-temporal areas), but can involve other regions (van Vliet et al., 2003). Episodes of pain are abruptly manifested with visual aura reaching maximum level in approximately 15 minutes and lasting up to 3 hours. Ipsilateral signs of autonomic response may usually be present, such as lacrimation, rhinorrhoea, nasal congestion, forehead and facial perspiration, myosis, ptosis, eyelid edema, conjunctival injection and temporal arterial inflammation. The pain is normally periodic and present for 8 weeks, 1 to 8 attacks occurring daily, accompanied by 6month to 2-year remission periods (Dodick et al., 2000).

\section{CLINICAL REPORT}

A 50-year-old woman was sent from an otolaryngology clinic to an orofacial disorders' center as she was suffering from headaches and craniofacial pain. The patient had had severe pain for 7 years with unilateral presentation (right-hand side), which did not subside with pharmacologic (AINES, triptans and indometacine) and oxygen management. The episodes of pain lasted 4 or 5 months with 3- or 4-month remission periods between the painful onsets. The headaches presented an episodic pattern (1 to 3 attacks daily) lasting three to six hours. Present pain intensity was measured on a 1-to-10 Visual Analogue Scale (VAS), 10 being the worst possible pain experienced by a patient; the patient in question was rated 8 on the VAS. She described the headache as starting during the night while she was asleep and waking her up. There was no history of snoring or episodes of apnea. Intraorbital pain was associated with complete presentation of autonomic signs and symptoms: lacrimation, conjunctival injection, rhinorrhoea, nasal congestion, forehead perspiration, myosis and edema of the eyelid. Additionally, the patient also reported xerostomy, intraoral metallic taste, visual hypostesia and secondary scalp hyperalgesia during the episodes of pain.

Craniofacial pain was exhibited having an anteriorposterior itinerary from the right eye to the ipsilateral suboccipital zone involving the ear and superior maxilla. No cigarette or alcohol consumption was reported. Each episode lasted too long (6 hours) to be a conventional cluster headache (according to diagnostic criteria); a probable cluster headache was therefore diagnosed.

A temporomandibular disorder (TMD) was also found consisting of left-hand side TMJ capsulitis and local muscle soreness in chewing muscles with bilateral temporal tendonitis. Dental evaluation revealed an unstable maxillary denture occluding natural mandible teeth. Prosthesis retention and stability was compromised with compression on the palatine incisive papilla. Moreover, an over-closed over-bite with altered vertical dimension was observed. The incisive papilla was intraorally positioned in the anterior residual ridge crest towards the vestibule area due to severe reabsorbed maxillar alveolar crest (Fig 1). The patient had used five prosthetic sets continuously ( $24 \mathrm{~h}$ ) for 20 years and the current prosthesis was 7 years old (when these headaches started).

The maxillary denture rested on reabsorbed maxillary bone and hyper-movable anterior crest with marked incisive papilla. The prosthesis bordered and pressured this papilla irritating this area (Fig. 2). The prosthesis was alleviated in this area during the first appointment to eliminate erythema and inflammation, although the patient did not express pain. This procedure was made because a replacement manufacture of the old prosthesis was accorded with the patient

An appointment was scheduled at the otolaryngology clinic for a sphenopalatine ganglion (SG) block following the above evaluation. The patient had been checked during a previous appointment at the orofacial disorders' center before the SG block procedure was begun; she reported spontaneous healing of her symptomatology. The patient was instructed to estimate her degree of relief on a 1-to-10 VAS scale (10 being the initial pain experienced by the patient). It was established that the pain had diminished from 10 to 1 on the VAS. When asked about referred and autonomic 
symptomatology, she stated that total resolution of these symptoms had occurred. The SG block was then stopped due to accidentally the pain finished. The relief of pain was measured during the second week, using VAS again; it was 0 over 10 . The patient has been periodically checked over a 5 years and 6 months period since, without recurrence of her pain and autonomic symptomatology.

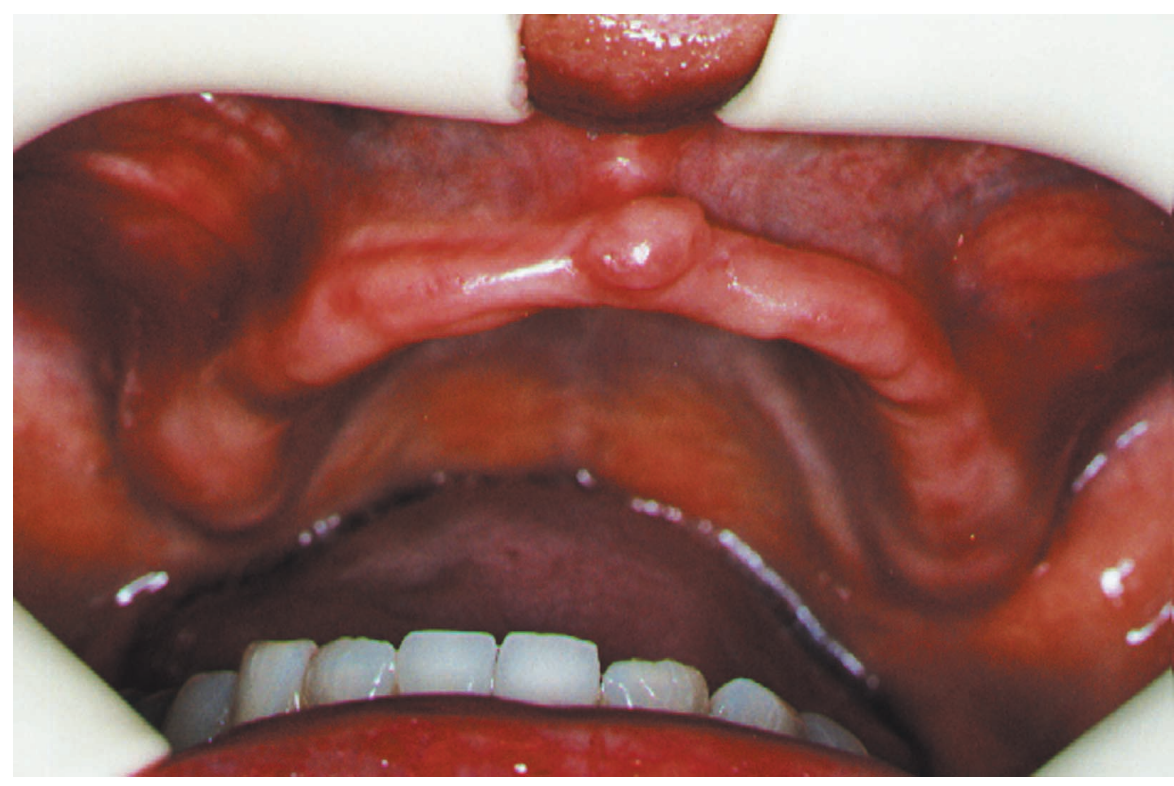

Fig 1. Incisive papilla zone over severe reabsorbed anterior crest.

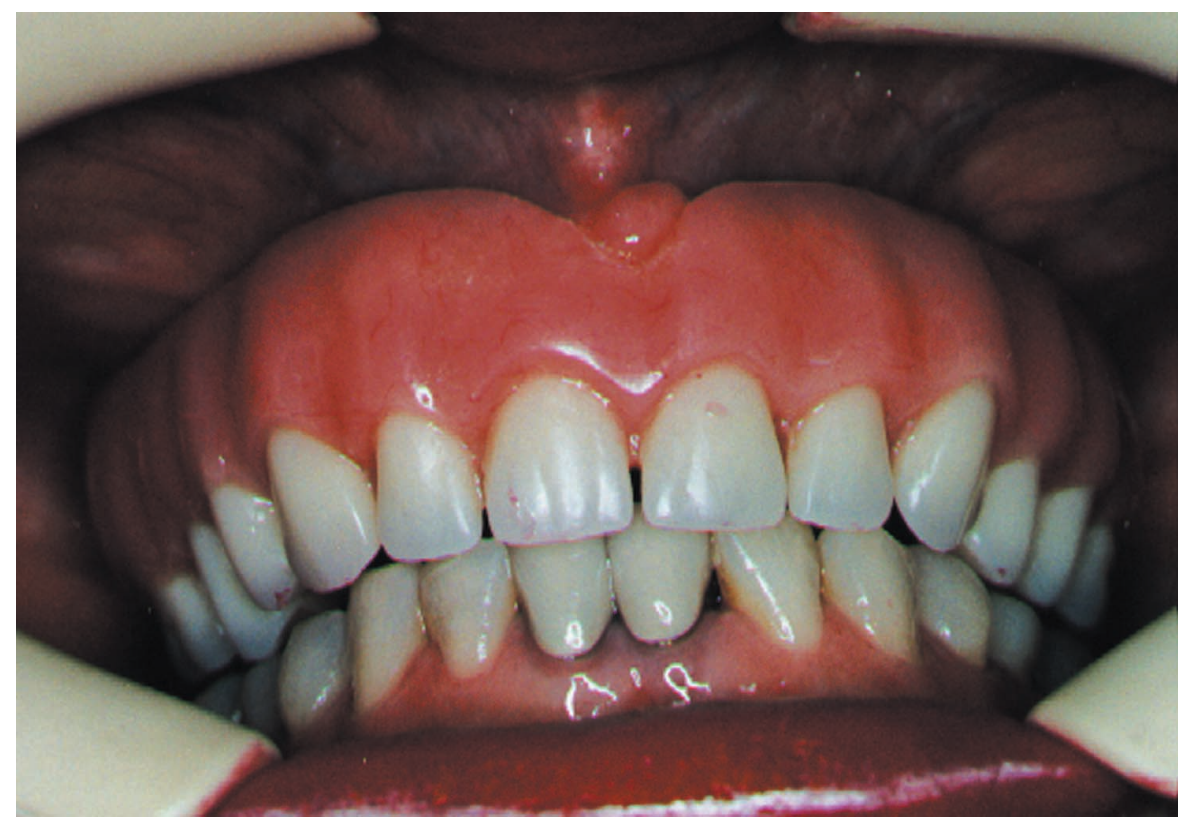

Fig 2. Prosthesis pressuring incisive papilla zone.

\section{DISCUSSION}

Differential diagnosis must be made with pathologies concerning autonomic system involvement in symptomatic presentation. Trigeminal branch participation accompanied by vegetative symptoms is known as trigeminal autonomic cephalalgias (TAC). Among the closest pathologies, paroxysmal hemicrania, SUNCT syndrome and neurovascular variants must be discarded because of the similar vegetative symptoms so presented; however, the sudden appearance, localization, intensity, and paroxistic presentation of these pathologies make the difference. The anatomical connections from the incisive papilla, the vascular patterns and the somatosensorial distribution may clarify the referred symptoms and the pathophysiological justification based on these associations.

Moskowitz affirms that the trigeminal nerve provides algesic afference routes in the pathophysiology and the transmission of headache in humans. Stimulating the trigeminal nerve results in dural vessel dilatation. The ophthalmic and maxillary branches of the trigeminal nerve innervate the cerebral, cerebellar posterior and basilar arteries, as well as the dural and pial arteries and the medial and anterior fossa. Signs of peripheral chronic pain, as in this patient, can arise from adverse conditions affecting the trigemino-vascular neurons thereby producing alteration in the vascular brain flow, no single central origin initiating these headaches' vascular events. Massive vascular effects on efferent nerves can be expected when it is taken into account that the abnormal sensorial and vegetative input coming from the incisive papilla trauma can excite potent vasodilator-mediated afferent nerves (Ertsey et al.). 
The trauma in the incisive papilla area can involve nociceptive, sympathetic and parasympathetic sensorial impulses. Stimulating the neurovascular network which emerges from the incisive foramen in the incisive papilla area can bring relevant somatosensorial and autonomic consequences. The incisive papilla receive innervation from the trigeminal maxillar branch (V2) taking its autonomic component from the SG. This ganglion receives its autonomic component from the pterygoid channel nerve (vidian nerve). This nerve's sympathetic component (deep petrosal nerve) comes from the common carotid plexus and the superior cervical sympathetic ganglion. The parasympathetic or secretomotor component (greater petrosal nerve from SG) comes from the upper salivatorius nucleus having fibers which are shared with the facial nucleus (intermedius nerve). The SG provides vegetative and somatosensorial terminals for the incisive papilla, through the nasopalatine nerve, and a wide neighboring area including the nasal septum, hard palate, soft palate, pharynx, nasal mucous and lachrymal gland areas (Goadsby \& Edvinsson).

Sphenopalatine artery (greater incisive artery) septal branch irrigation emerges in the incisive papilla area providing irrigation for the nasal septum; this is mixed with the superior lip and ophthalmic artery and also vasomotorinnervated by the SG. The ganglion is the lachrymal, minor salivary, nasal and pharynx glands' secretomotor component. Activating vegetative neurons in the pterygopalatine ganglion produces cranial blood vessel vasodilatation, secretomotor activation and sensitization of the trigeminovascular afferents (neurogenic inflammation) due to the presence of an inflammatory mediator (Jänig).

The above explains why sympathic and parasympathic complex neurovascular anatomy stimulation in the palatine area produces autonomic changes resembling a probable cluster headache. Parasympathic stimulation in the area can dilate the intraoccular blood vessels and raise blood-pressure. Such vegetative activation also generates occular conjunctive and nasal vessel expansion. Hardebo has explained how neuron stimulation of the trigeminal nerve in the cornea, iris and around blood vessels (derived from ciliary and conjunctival arteries) causes vasomotor responses in the choroidal artery thereby increasing intraoccular pressure and explaining the pain, hypoesthesia and autonomic changes to the patient's right eye. This kind of vegetative activation can also explain changes in perspiration and higher frontal temperature (Gottselig \& Messlinger).

The patient told of a diffuse craniofacial pain accompanied by a sensation of disesthesia caused by constant painful stimulus over a 7 -year period. The pattern of pain was explained as being a heterotopic presentation, including projected pain from V2 and referred pain from central excitatory effect coming from the incisive papilla's neurovascular area (Sessle et al.). The trigeminal nerve's (subnucleus caudalis) spinal nucleus neurons receive these craniofacial nociceptive signals which can suffer nerve plasticity and mistake the cortical location of the source of pain caused by the sensitization of non-related afferent interneurons.

Muscular involvement further complicated the pain experienced by this particular patient, leading to a more multifaceted symptomatic presentation, making its diagnosis difficult. Such symptomatology can create a state of protective muscular adaptation to prevent the pain, producing a painful cycle of muscle-skeletal dysfunction which can also produce secondary TMD (Lund et al., 1991).

Periodic presentation of cluster and probable cluster headaches stresses the difficulty of emphasizing that remission of pain and its associated autonomic symptomatology in this patient was achieved by the accidental alleviation of the incisal papilla pressure. The above pathophysiological scenario, involving evoked peripheral pain signals integrating ANS, cannot exclude the fact that a change in vegetative headache may be CNS expression reflected in sensory somatomotor, autonomic and neuroendocrine changes due to central somatosensory cortex-mediated abnormalities and hypothalamus-modulating nociceptive input (van Vliet et al.). However, the findings from this clinical report provide a valid new perspective in orofacial differential diagnosis pain origin in spite of the probable intraoral cause and prothesis alleviation procedure seeming so coincidental with the end of the cluster headache that had lasted by 5 years. It is difficult to determine whether or not the pain relief was a coincidence or not but periods of intense headache, followed by liberation from such pain, has not happened again during the last almost five years. Also, it should be stressed that the last prothesis was worn for 7 years (when these headaches started) and that painful episodes lasted four or five months, with three or four months' remission between painful onsets. Integrating different pathophysiological models (peripheral and central) can be especially remarkable when no unifying explanation of cluster headache is yet available and cavernous sinus hypothesis, periodicity (circadian rhythm), mitochondrial dysfunction and trigeminovascular-parasympathetic pathways have failed as individual justification (Dodick et al.).

Diagnosing a cluster headache can be a complicated task due to variable pain localization and its episodic presentation added to possible intraoral traumatic origin. Interdisciplinary management, including a dental specialist in craniofacial pain, offers a key tool to medical staff during these symptoms' conservative phase. Clinical success 
depends on each specialist's ability to study the different aspects of the same problem. Doctors specializing in just one discipline cannot always solve a patient's symptomatology by themselves unless aided by the invaluable support of a multidisciplinary management team.
Every specialist contributes his/her specific knowledge towards differential diagnosis addressing a correct treatment plan. This clinical study represents a useful tool in the differential diagnosis origin of painful orofacial neurovascular disorders.

RAMIREZ, L. M.; BALLESTEROS, L. E. \& SANDOVAL, G. P. Cefalea autonómica trigeminal por compresión neurogénica palatina: Reporte de caso y revisión. Int. J. Morphol., 25(3):591-596, 2007.

RESUMEN: Se presenta un caso de cefalea autonómica trigeminal que simula una cefalea en cluster probable con potencial origen traumático intraoral. Mujer de 50 años que reportaba dolor derecho de intensidad severa con 7 años de evolución. El dolor se presenta con síntomas vegetativos como epifora, irritación de la conjuntiva ocular, rinorea, congestión nasal, sudoración frontal, miosis y edema palpebral. Los episodios de dolor se presentaban intermitentemente en el año, con duración de 4 a 5 meses y periodos de remisión de 3 a 4 meses. Las cefaleas se presentaban de manera episódica en el día (1 a 3 episodios) que duraban de 3 a 6 horas. Se observa prótesis intraoral en mal estado, con 7 años de realizada. La paciente reporta la elaboración de 5 juegos protésicos hasta la fecha y que usa constantemente en el día y la noche. Accidentalmente, y antes de la remisión a otro especialista, los síntomas desaparecen después del alivio mecánico en la zona anterior de la prótesis, que comprimía e irritaba la papilla incisiva. La paciente ha estado bajo controles periódicos durante 5 años y medio, sin recurrencia de los síntomas. La posible fisiopatología es discutida.

PALABRAS CLAVE: Ganglio esfenopalatino; Papila incisiva; Dolor neurovascular; Dolor referido; Desórdenes témporomandibulares.

\section{REFERENCES}

Albertyn, J, Barry M, Odendaal CL. Cluster headache and the sympathetic nerve. Headache, 44:183-5, 2004.

Appelbaum, J. \& Noronha, A. Pericarotid cluster headache. J. Neurol., 236:430-1, 1989.

Bouhassira, D.; Attal, N.; Estève, M. \& Chauvin, M. "SUNCT" syndrome. A case of transformation from trigeminal neuralgia? Cephalalgia, 14:168-70, 1994.

Cremer, P. D.; Halmagyi, G. M. \& Goadsby, P. J. Secondary cluster headache responsive to sumatriptan. J. Neurol. Neurosurg. Psychiatry, 59:633-4, 1995.

Dodick, D.W.; Rozen, T. D. Goadsby, P. J. \& Silberstein SD. Cluster headache. Cephalalgia, 20:787-803, 2000.

Ekbom, K.; Svensson, D. A.; Traff, H. \& Waldenlind, E. Age at onset and sex ratio in cluster headache: observations over three decades. Cephalalgia, 22:94-100, 2002.

Ertsey, C.; Hantos, M.; Bozsik, G. \& Tekes, K. Circulating nociceptin levels during the cluster headache period. Cephalalgia, 24:280-3, 2004.

Evers, S.; Soros, P.; Brilla, R.; Gerding, H. \& Husstedt, W. Cluster headache after orbital exenteration. Cephalalgia, 17:680-2, 1997.
Formisano, R.; Angelini, A.; De Vuono, G.; Calisse, P.; Fiacco, F. \& Catarci, T. Cluster-like headache and head injury: case report. Ital. J. Neurol. Sci., 11:303-5, 1990.

Gawel, M. J.; Willinsky, R. A. \& Krajewski, A. Reversal of cluster headache side following treatment of arteriovenous malformation. Headache, 29:453-4, 1989.

Goadsby, P. J.; Matharu, M. S. \& Boes, C. J. SUNCT syndrome or trigeminal neuralgia with lacrimation. Cephalalgia, 21:82-3, 2001.

Goadsby, P. J. \& Edvinsson, L. The trigeminovascular system and migraine: studies characterizing cerebrovascular and neuropeptide changes seen in humans and cats. Ann. Neurol., 33:48-56, 1993.

Gottselig, R. \& Messlinger, K. Noxious chemical stimulation of rat facial mucosa increases intracranial blood flow through a trigemino-parasympathetic reflex - an experimental model for vascular dysfunctions in cluster headache. Cephalalgia, 24:206-14. 2004.

Hannerz, J. A case of parasellar meningioma mimickmg duster headache. Cephalalgia, 9:265-9, 1989.

Hardebo, J. E. The involvement of trigeminal substance P neurons in cluster headache and hypothesis. Headache, 24:294-304, 1984. 
Headache Classification Committee of The International Headache Society. The International Classification of Headache Disorders (second edition). Cephalalgia, 24(Suppl 1):1-160, 2004.

Heidegger, S.; Mattfeldt, T.; Rieber, A.; Wikstroem, M.; Kem, P.; Kem, W. et al. Orbito-sphenoidal Aspergillus infection mimicking cluster headache: a case report. Cephalalgia, 17:676-9, 1997.

Jänig W. Relationship between pain and autonomic phenomena in headache and other pain conditions. Cephalalgia, 23 (Suppl. 1):43-8, 2003.

Koenigsberg, A. D.; Solomon, G. D. \& Kosmorsky, G. Pseudoaneurysm within the cavernous sinus presenting as cluster headache. Headache, 3-1:111-3, 1994.

Kudrow, L.; Mcginty, D. J.; Philips, E. R. \& Stevenson, M. Sleep apnea in cluster headache. Cephalalgia, 4:33-8, 1984.

Lund, J. P.; Donga, R.; Widmer, C. G. \& Stohler, C. S. The pain adaptations model: A discussion of the relationship between chronic musculoskeletal pain and motor activity. Can. J. Physiol. Pharmacol., 69:683-94, 1991.

Martins, I. P.; Gouveia, R. G. \& Antunes, J. L. Double dissociation between autonomic symptoms and pain in cluster headache. Cephalalgia, 25:398-400, 2004.

Melis, M.; Zawawi, K.; al-Badawi, E.; Lobo, S. \& Mehta, N. Complex regional pain syndrome in the head and neck: A review of the literature. J. Orofacial Pain, 16:93-104, 2002.

Moskowitz, M. A. Neurobiology of vascular head pain. Ann Neurol., 16:157-68, 1984.

Muñoz, C.; Tejedor-Diez, E.; Frank, A. \& Barreiro, P. Cluster headache syndrome associated with middle cerebral artery arteriovenous malformation. Cephalalgia, 16:202-5, 1996.

Piovesan, E. J.; Lange, M. C.; Werneck, L. C.; Kowacs, P. A. \& Engelhorn, A. L. Cluster-like headache. A case secondary to the subclavian steal phenomenon. Cephalalgia, 21:850-1, 2001.

Putzki, N.; Nirkko, A. \& Diener, H. C.Trigeminal autonomic cephalalgias: a case of post-traumatic SUNCT syndrome? Cephalalgia, 25:395-7, 2004.

Romoli, M. \& Cudia, G. Cluster headache due to an impacted superior wisdom tooth: case report. Headache, 28:135-6, 1988.
Rosebraugh, C. J.; Griebel, D. J. \& DiPette, D. J. A case report of carotid artery dissection presenting as cluster headache. Am. J. Med., 102:418-9, 1997.

Rozen, T. D. Atypical presentations of cluster headache. Cephalalgia, 22:725-9, 2002.

Sacquegna, T.; D'Alessandro, R.; Cortelli, P.; De Carolis, P. \& Baldrati, A. Cluster headache after herpes zoster ophthalmicus. Arch. Neurol., 39:384, 1982.

Sessle, B. J.; Hu, J. W.; Amano, N. \& Zhong, G. Convergence of cutaneous, tooth pulp, visceral, neck and mussle afferents onto nociceptive and non-nociceptive neurons in trigeminal subnucleus caudalis (medullary dorsal horn) and its implications for refered pain. Pain, 27:219-35, 1986.

Sjaastad, O. \& Bakketeig, L. S. Cluster headache prevalence. Vaga study of headache epidemiology. Cephalalgia, 23:528-33, 2003.

Soros, P.; Frese, A.; Husstedt, I. W. \& Evers, S. Cluster headache after dental extraction: implications for the pathogenesis of cluster headache? Cephalalgia, 21,61922, 2001.

Taub, E.; Argoff, C. E.; Winterkorn, J. M. S. \& Miihorat, T. H. Resolution of chronic cluster headache after resection of a tentorial meningioma: case report. Neurosurgery, 37:31922, 1995.

Tfelt-Hansen, P.; Paulson, O. B. \& Krabbe, A. Invasive adenoma of the pituitary gland and chronic migrainous neuralgia. A rare coincidence or a causal relationship? Cephalalgia, 2:25-8, 1982.

van Vliet, J. A.; Vein, A. A.; Le Cessie, S.; Ferrari, M. D. \& van Dijk, J. G. Impairment of trigeminal sensory pathways in cluster headache. Cephalalgia, 23:414-9, 2003.

West, P. \& Todman, D. Chronic cluster headache associated with a vertebral artery aneurysm. Headache, 31:210-2, 1991.

Dirección para correspondencia:

Dr. Luis Miguel Ramirez

Calle 45 NN$^{\circ} 33-17$. Apto 702B

Edificio La Nacional

Bucaramanga-Colombia.

COLOMBIA

Email Imra3@yahoo.com

Received: 09-06-2007

Accepted: 10-07-2007 